\title{
CONCEPTS OF LOAD HANDLING DEVICES, ADJUSTED TO LIGHT GOODS VEHICLES OF THE WEIGHT UP TO 3.5T
}

The main aim of the article is to present three concepts of load handling devices, adjusted to light goods vehicles of the weight up to 3.5 t. The design issue commissioned by Poczta Polska - the Polish Post was analysed. On the basis of the analysis the design assumptions were taken to design a device. The construction and the method of operation of the design structures suggested by the author were discussed. All the concepts were compared with one another with the use of a SWOT analysis.

Keywords: Load handling devices, loading board, postal transport.

\section{Introduction}

The process of the goods unloading may be aided with the use of stationary and mobile devices. Moreover, some devices facilitating unloading may be placed on the vehicles. The examples of the stationary devices located in fixed places, where the goods are being relocated, are: cranes, gantry cranes, conveyors, compressors and pumps dedicated to reloading liquid and dry goods. As far as reloading devices are concerned, though, they are among others: forklifts, loaders, straddle carriers and lift trucks [1 and 2].

The idea of placing reloading devices on the vehicles has numerous advantages. The most vital one is the independence from accessibility of mobile reloading devices in the target unloading or reloading place. It fastens the whole process of goods transportation [3 and 4]. That is why such devices are, depending on the possibilities and needs, more and more often mounted on transporting vehicles. The examples of such devices may be: loading platforms, lorrymounted cranes, movable floors, dump bodies (in case of unloading) [1].

According to PN-EN 1756-1 norm from November 2008, an access loading platform is defined as an elevating device to be installed on or inside a wheeled vehicle that is used to reload or unload this vehicle [5]. Loading platforms are often called cargo winches or load boards. Such devices are often used in delivery vans or lorries. Loading platforms are also often installed on semitrailers or trailers. Such devices are designed to elevate goods placed on the pallets, in carts, baskets, cases, containers, packets and others. It must be stressed out, though, that the use of a loading platform eliminates the most burdensome and laborious part of work connected with reloading [6 and 7]. Loading platforms are especially useful during distribution of large amounts of goods placed on pallets. They enable loading and unloading goods by just one person with the use of pallet trucks [8].

The aim of this article is to present three conceptions of devices realising the procedure of goods reloading, with special attention paid to construction and mode of operation of the described mechanisms. The present article consists of four parts. The first one focuses on the construction problem that the authors faced. The second one discusses construction assumptions and describes what requirements should the created construction meet to operate safely and effectively. The following part presents three variants of devices realising the procedure of goods reloading, their essence and construction. In the summary, all concepts are compared and, with the use of the SWOT analysis, the best one is chosen.

\section{Problem analysis and specification}

The problem that is the subject of the article was reported by the Lublin branch of PocztaPolska (Polish Mail hereinafter referred to as PP). The institution had ordered the project that was aimed at rationalising the reloading procedure

\footnotetext{
* ${ }^{1}$ Pawel Drozdziel, ${ }^{1}$ Kamil Wawer, ${ }^{2}$ Radovan Madlenak, ${ }^{3}$ Murat Omarbekovich Mussabekov

${ }^{1}$ Institute of Transport, Combustion Engines and Ecology, Lublin University of Technology Lublin, Poland

${ }^{2}$ Faculty of Operation and Economics of Transport and Communications, University of Zilina, Slovakia

${ }^{3}$ Kazakh Academy of Transport and Communications named after M. Tynyshpayev, Almaty, Kazakhstan

E-mail: p.drozdziel@pollub.pl
} 
in wagons in the Lublin branches of PP. A person who is directly responsible for and takes part in the reloading process is the driver of a light commercial vehicle. Light commercial vehicles are some of the most common vehicles on the roads of many cities [9]. The project solution is dedicated to the following types of wagons: Peugeot Boxer, Fiat Ducato, Mercedes Sprinter, etc.

The drivers of delivery vans are obliged to deliver the parcels safely and in due time from the central base located in the city suburbs to the local PP branches within the whole area of the city of Lublin.All loads (letters and parcels) are packed into special cover boxes. An empty cover box weighs $1 \mathrm{~kg}$, and a fully loaded- $10 \mathrm{~kg}$. Cover boxes are designed to make it possible to put them on top of one another. For more efficient and comfortable displacing, cover boxes are equipped with handles. The process of the cover boxes' loading and unloading is carried out manually. A driver is able to lift 5 boxes weighing ca. $50 \mathrm{~kg}$ at once, and walk a certain distance. At every target point, the driver has to unload the loads he needs and then load new goods. Both of these operations are carried out manually. It is connected with the driver's stepping on the load bed floor and displacing the load multiple times. Such type of the loading-unloading process organisation requires substantial effort on the part of the driver, which is, in turn, a cause of frequent injuries. Loading is time-consuming, which influences the decrease in the transport effectiveness.

The target solution assumes loading the cover boxes on specially designed transportation carriages. In order to decrease the workload on the part of the driver and time of the goods loading and unloading, it is necessary to use the rationalising construction. The introduction of the new solution will facilitate the driver's work and reduce the transportation time. A steel transportation carriage designed for vehicles owned by PP is an example of such solution.

\section{Construction assumptions of the project}

Construction assumptions of the project describe the device's working, its exploitation conditions and requirements that it will have to meet [10]. While working on the reloading construction's conception dedicated to delivery vans, eight construction assumptions were introduced. A part of them results from the nature of work of the reloading devices, while the other ones were proposed by the client.

1. User's safety.

2. The construction's load capacity up to $500 \mathrm{~kg}$.

3. Lift height, which is equal to distance between the ground and the level of the van's load bed floor.

4. Low unladen kerb mass between $150 \mathrm{~kg}$ and $250 \mathrm{~kg}$.

5. Minimised construction size.
6. The device's construction will not interfere with the van's construction.

7. Construction's reliability.

8. Low maintenance costs and accessibility of the used parts.

These assumptions determine the range of solutions that may be used to work on the technical problem and define the character of the elements that meet the defined challenges.

\section{The conceptions of the construction problem's solutions}

This part of the article presents three variants of the construction problem's solutions. The construction and principle of operation of each design are described. Advantages and disadvantages of solutions are analysed and referred to the construction assumptions.

\subsection{The scissor lift conception}

The first conception is a mobile platform with scissor lift driven by an electric motor. A mechanism responsible for lifting the load is a scissor lift. It is widely used in garages to lift the cars. The construction consists of electric motor, toothed gear, screw, screw cap, bearing with bearing mounting, strands, loading platform, wheels, transport grip and beams with limit switches. All the elements of the designed reloading device are placed on a perpendicular frame made of structural sections. The driving torque of the scissor lift is provided by a constant voltage electric motor. The size of the driving torque is changeable due to the use of the toothed gear. The toothed gear's output was connected with the power screw. Rotation of the screw triggers feed of the cap that has pinned connection with one of the strands' ends. Rotary movement of the screw results in up or down movement of the strands. Aluminium loading platform where the load is placed is attached to another end of the strands.

In order to impose the right work upon the platform, two limit switches are attached to the frame. They are responsible for cutting the power supply off of the motor when the minimum of maximum lift height of the platform is achieved. In order to work well, the main limit switch is attached to a fold-up beam. The beam must be placed in vertical position before turning the platform on. When the reloading is finished, the beam must be lowered. In order to facilitate the transport, wheels and transport grip will be attached to the platform frame. The motor will be supplied with the use of buffer from accumulator and alternator. Total construction mass will not exceed $25 \mathrm{~kg}$.

The advantage of the presented solution is the adjustable height of the load lift. It is realised thanks to the increased 
number of motor rotations and, thus, through the increased screw cap feed in the cap-screw system. Moreover, one must take into consideration that with the planned components configuration, the planned platform mass is much lower than the proposed one in the construction assumptions, which is a considerable advantage. In addition, when choosing the electric motor with parameters able to provide the load capacity of the whole construction weighing a half of tone, the second construction assumption relating to the system's load capacity is complied with as well. It should be noted that when folded, the platform size is considerably small.

A disadvantage of the scissor lift is the mode of the electric motor supply. The conception assumes the power feed supply with the use of a built-in accumulator and alternator. Such solution requires an interference with the electric supply of the vehicle and installation of an additional group of conductors and power supply sockets in the van. Since the platform is not attached to the vehicle, a driver will be forced to take it out from the case before each and every use, which requires additional effort on his part. Moreover, everyday control of the accumulator condition must be taken into consideration as well. The proposed construction may be susceptible to external conditions, such as vibration, hits, dirt, that may considerably decrease its reliability. What is more, when the mechanism is broken, the costs of service may be relatively high - especially in the case of the electric motor damage.

\subsection{The lever-spring conception}

The second proposition of the construction aimed at rationalising the loading and unloading processes, is a mobile loading-unloading platform with a lever-spring drive. The conception is based on a lever-spring mechanism that is used, among others, in the furniture assembly. The device consists of frame, strands, pins, platform, gas spring, ratchet mechanism and steering handle. The device's base is a rectangular frame made of structural sections. The frame is equipped with wheels in order to position the construction against a delivery van. Four strands of the same length are attached to the frame so that the ends of the two of them are installed at the opposite sides of the frame. Strands have pinned connection with the frame, which enables them to move on the circle. The connection of strands with the base is realised with the use of pins. An aluminium loading platform has pinned connection with another strand's end. A steering handle controlling the loading platform's position is attached to one strand. A maximum height of the platform is equal to joints' spacing in the pins.

Moreover, gas springs enhance the platform lowering. A mounting rod is placed crosswise through the middle of the opposite strands pair. It is responsible for fastening the first joint to the gas springs. The catch pawl of the gas spring's piston rod is attached to the base frame. A key aspect in this case is to choose the appropriate parameters of the spring. The force that aids lifting should be high enough to lift the platform and, at the same time, limited to a safe value in order to provide a controlled platform lift. An appropriate piston rod stroke must be selected. It is possible to add a mechanism to control the platform lift. A ratchet mechanism may be mounted as well. Depending on the platform lift, this mechanism maintains the load at the requested height. Moreover, the ratchet mechanism protects from a sudden failure of the gas spring.

The advantage of the construction is a possibility to adjust the lifting height with regard to the position of the van's load bed floor. The use of ratchet mechanism allows for stopping the platform at the requested height. Another advantage is relatively low unladed kerb mass, similar to the scissor lift. The device, in the proposed configuration, does not take much space, which increases the van's loading capacity. The proposed solution does not interfere with the vehicle construction. It is a separate mechanism aimed at lifting the loads. Moreover, this construction does not require using specialised parts, which decreases the production costs.

As far as the disadvantages are concerned, it is necessary to position the platform against the vehicle's load bed floor. The device must be set in a position that enables to transport the load from the platform to the van's load bed floor. In addition, gas springs aid the mechanism's work at the fixed loads. It means relatively narrow range of possible load weight that will allow for the faultless work of the system. What is more, the platform is susceptible to external conditions, such as vibration, dirt or hits.

\subsection{The mechanical loading platform with unfaced surface conception}

The third conception that was proposed is a mechanical loading lift. This proposition was based on the idea of loading lifts driven hydraulically. Its characteristic is the fact that when folded (the platform is inside the vehicle's loading space), the top elements of the device are not faced with each other.

The mechanical loading platform with unfaced surface consists of: work-rest blades with strengthening elements and fixing kits, support rollers with fixing flat bars, frame bearer, rope winch, steel cable, blocks, support wheels, support wheels' blocking mechanism, a rod connecting support wheels with platform and reinforcing strands with slide ways. Aluminium or steel work support blades are attached to the vehicle floor with the use of fixing kits. As opposed to the previous conceptions of the reloading device, 
the third proposition is based on the combination of loading lift with the vehicle's load bed floor. It is, though, based on the project assumption that excludes the possibility of the vehicle construction's modification.

Reinforcing elements in the form of aluminium or steel flat bars are welded between the work support blades. The reinforcing elements system creates a frame that is to stabilise and bind all the work support blades. The work support blades are presented in Fig. 1 with number 1. The work support blades are, in substance, a flat bar with a perpendicular oblong cut milled on its surface. Such cut is to drive the support rollers. The rollers are attached to the frame bearer with the use of fixing flat bar. The flat bar was cut out of a sheet metal plate and welded in the frame bearer.

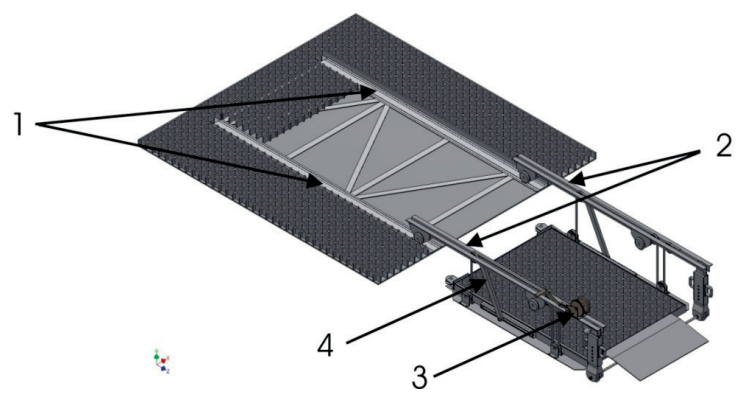

Fig. 1 Figure of loading space with mechanical loading platform with unfaced surface

The frame bearer consists of two non-equal-sided angles. They were attached with the use of welded standoffs. Such solution creates a spare space between the surfaces of angles' legs. The longer legs of the angles are oppositely directed. The shorter legs of the angles are faced. The holes aimed to drive the pins blocking the slid able platform position, are cut on one end of the frame bearer's angle. Frame bearer with support rollers are presented in Fig. 1 with number 2. The rope winch is attached to the faced surface of the frame bearer with the use of screws or blind rivets. The winch's characteristic is friction brake and ratchet mechanism, thanks to which it is possible to suspend and stop the load at the requested height. Due to change diameter of winch's cylinder, it is possible to adjust time of lifting cargo.

A steel cable with a hook is reeled on the rope winch's hoisting drum. The cable is driven through the system of mobile and immobile blocks that are responsible for the distribution of internal forces during the load lifting.

The blocks are attached to the frame bearer between the angles' legs with the use of pin and sleeves. In this system, they are treated as immobile blocks. The blocks are chosen in such a way to ensure that their load capacity is higher than internal forces in the cables. There are possibility to increase the weight of cargo due to choose proper blocks, it means block with proper bearing. The blocks model and their attachment are presented in Fig. 1 with number 3.

Support wheels have pinned connection with the end of frame bearers, from the vehicle's side, between the angles. Their task is to hold the frame bearer in horizontal position and to transfer internal loads when lifting the platform with the load.

In order to provide a regulated height of the support wheel, two closed profiles of different sizes and placed telescopically were used. The profiles' characteristics are holes cut on the lateral surface of the walls. Determining the support wheel's height and blocking the line feed is carried out with the use of a pin build-in concentrically in the profiles' holes. The porters are attached to the outer profile, thanks to which an operator is able to rotate the support wheels and determine the angular orientation. A wheel enabling the support wheel's and, at the same time, the whole platform's feed is mounted on the inner profile.

A mechanism blocking the support wheels' position is attached to one end of frame bearer, from the vehicle's side. It consists of a handling plate with a porter, aluminium or steel mounting angle, blocking pins with variable diameter and a return spring. Blocking mandrels from the smaller diameter's side were welded to the end face of the handling plate with a porter. The characteristic of the blocking mandrels is the change of diameter in a stepped manner. Spacing of pins attached to the plate corresponds to the spacing of holes cut in the frame bearer. The mechanism's task is to block the extreme positions of the support wheels. It is realised with the use of concentric inserting of the blocking pins into the holes placed in the mounting angle, frame bearer angle and on the bearing surface of the support wheel. After passing all the holes, the pin is in the off-position.

The loading platform's landing consists of angles, landing grid and blocks. The loading platform's frame is made of aluminium angles. They are welded in a rectangular shape. One leg of all angles is turned inward the frame space. Moreover, additional angles were welded with the longer sides of the rectangular landing. Unwelded legs of the inner angles create the seating surface of the landing grid, where the load will be placed. The blocks are attached to the unwelded legs of outer angles. In the frame bearer-landing system, they are treated as immobile blocks. Two additional blocks are attached to the end face of the landing's shorter side. They are placed on the extreme ends of the angle. Moreover, in order to facilitate putting the load on the platform, a tracking frame is attached to the landing. It is mounted with the use of hinges. Between the frame bearer's angles, the aluminium strands are mounted. Their task is to eliminate moving of the platform perpendicularly to the vehicle's length and to stabilise the platform. One side of strands has the pinned connection between the angles. The other side is connected with the work 
support blade with the use of a pin. The work support blade is welded to the platform landing. The platform's move stabiliser is presented in Fig. 1 with number 4.

The manner of the loading platform operation is similar to the classic loading lifts driven hydraulically. When folded, the landing, together with the frame bearer and support wheels, are placed in the vehicle's loading space. The operator pulls the frame bearer out of the loading load bed floor by pulling the handles placed on the support wheels. When the support wheels are beyond the van's loading area, the operator releases the hold of the support wheels position by pulling the handling plate. It allows for the $180^{\circ}$ rotating of the support wheels. The supports are blocked in extreme positions.

This conception's advantage is an easy way to regulate the platform loading capacity. The use of blocks and an appropriate cable allows for regulating the whole device's loading capacity. The load capacity may be easily increased by changing the rollers number. Moreover, the use of the rope winch enables a smooth regulation of the lifting height. An important advantage of the rope winch construction is the friction brake with pawl that blocks the landing automatically on the requested height. Depending on the used materials, the anticipated unladen kerb mass of the construction is between $150 \mathrm{~kg}$ and $250 \mathrm{~kg}$. The conception of the platform with unfaced surface assumes mounting it to the original equipment of the van's load bed floor. It means the interference with the vehicle original structure. The parts the platform is made of are resistant to external conditions and difficult working environment. In addition, a majority of the platform components is catalogued and easily accessible, which considerably decreases the costs of manufacturing.

A very shape of the construction is its disadvantage. The frame bearer in folded position sticks out from the lining on the load bed floor.

\section{SWOT analysis of the different lifts conceptions}

According to the technical objects construction scheme, one of the three proposed conceptions was chosen. In order to compare all of them and choose the best one, the SWOT analysis was conducted. It is an effective method of the technical projects' strengths and weaknesses identification, and of opportunities and threats determination that are connected with implementation of a chosen conception [11].

Literature research and opinion of experts was used for the identification and classification of the most important internal and external factors in four categories [12]:

1. Strengths- characteristics of the project that give it an advantage over others

2. Weaknesses- characteristics that place the project at a disadvantage relative to others
3. Opportunities- elements that the project could exploit to its advantage

4. Threats- elements in the environment that could cause trouble for the project.

In chapter two, eight construction assumptions that guided the whole process of the construction problem solution were discussed. Table 1 presents the comparison of the conceptions and enumeration of the construction assumptions they meet.

Table 1 indicates that the third variant- the mechanical loading platform with unfaced surface- meets the highest number of the construction assumptions. Taking into consideration the fact that the other conceptions do not meet at least two construction assumptions, and by comparing opportunities and threats for the project, the third variant was chosen the best solution of the author's reloading device.

\section{Summary}

The article presents conceptions of devices facilitating the process of goods reloading. Based on discussions with the Management Board and interviews with drivers hired by Poczta Polska (Polish Mail), eight construction assumptions were accepted. They were a starting point for designing devices aiding the procedure of the parcels reloading.

The first conception is based on the use of an electric motor and a scissor lift mounted on a ramp. Power needed to feed the electric motor is supplied with the use of buffer from accumulator and alternator.

The second proposition is an autonomic device with gas springs. As in the first case, it is based on a frame made from sections. The construction consists of frame, strands and platform that have pinned connections. A handle attached to one strand regulates the platform's position.

The third project is a lifting platform mounted inside the vehicle's load bed floor. This solution was inspired by loading platforms driven hydraulically. In contrary to the available and used solutions, a power drive was used in the presented conception. The force needed to lift the load is decreased by using an appropriate system of blocks. The device's characteristic is the unfaced upper surface, unfaced frame bearer with the lining and floor surface.

There are a lot of other solutions available on the market offered by specialised engineering companies. However, it must be noted that the proposed device aiding the reloading procedure is dedicated to the client's needs, i.e. Poczta Polska (Polish Mail). The prepared conception is a compromise between the authors' design vision and the client's expectations. 


\begin{tabular}{|c|c|}
\hline \multicolumn{2}{|c|}{ Variant 1- The scissor lift conception } \\
\hline Strengths: & Weaknesses: \\
\hline $\begin{array}{ll}\checkmark & \text { User's safety } \\
\checkmark & \text { The construction's load capacity up to } 500 \mathrm{~kg} \\
\checkmark & \text { Lifting height } \\
\checkmark & \text { Low unladen kerb mass } \\
\checkmark & \text { Minimised construction's size } \\
\text { The number of the construction assumptions it meets: } 5 \\
\text { Opportunities: }\end{array}$ & $\begin{array}{c}\mathbf{x} \text { Interferences in the vehicle construction } \\
\times \quad \text { Relatively increased reliability } \\
\times \quad \text { High costs of prospective repairs and limited } \\
\text { accessibility of the catalogue parts } \\
\text { The number of the construction assumptions it does } \\
\text { not meet: } 3 \\
\text { Threats: }\end{array}$ \\
\hline - The possibility of customised modifications & $\begin{array}{l}\text { - A possible lack of support after launching the } \\
\text { series production } \\
\text { - A possible breach in patent law of the other scissor } \\
\text { lifts' producers. }\end{array}$ \\
\hline \multicolumn{2}{|c|}{ Variant 2: The lever-spring conception } \\
\hline Strengths: & Weaknesses: \\
\hline $\begin{array}{ll}\checkmark & \text { User's safety } \\
\checkmark & \text { Lifting height } \\
\checkmark & \text { Low unladen kerb mass } \\
\checkmark & \text { Minimised construction's size } \\
\checkmark & \text { The lack of interference in the vehicle construction } \\
\checkmark & \text { Low maintenance costs and accessibility of the used parts } \\
& \quad \text { The number of the construction assumptions it meets: } 6\end{array}$ & $\begin{array}{l}\times \text { Construction's reliability } \\
\times \text { The construction's load capacity up to } 500 \mathrm{~kg} \\
\text { The number of the construction assumptions it does } \\
\text { not meet: } 2\end{array}$ \\
\hline Opportunities: & Threats: \\
\hline $\begin{array}{l}\text { The possibility of the constructor's support due to the project's innovation } \\
\circ \quad \text { The possibility of the project development when it comes to lifting the loads } \\
\text { of the same height every time }\end{array}$ & $\begin{array}{l}\text { - The possibility of the lack of interest on the part } \\
\text { of companies due to the device's lack of versatility }\end{array}$ \\
\hline \multicolumn{2}{|c|}{ Variant 3: The mechanical loading platform with unfaced surface conception } \\
\hline Strengths: & Weaknesses: \\
\hline \begin{tabular}{ll}
$\checkmark$ & The construction's load capacity up to $500 \mathrm{~kg}$ \\
$\checkmark$ & Lifting height \\
$\checkmark$ & Low unladen kerb mass \\
$\checkmark$ & Minimised construction's size \\
$\checkmark$ & The lack of interference in the vehicle construction \\
$\checkmark$ & Construction's reliability \\
$\checkmark$ & Low maintenance costs and accessibility of the used parts \\
& \multicolumn{2}{c}{ The number of the construction assumptions it meets: 7}
\end{tabular} & $\begin{array}{l}\text { The number of the construction assumptions it does } \\
\text { not meet: } 1\end{array}$ \\
\hline Opportunities: & Threats: \\
\hline $\begin{array}{l}\text { The possibility of the constructor's support due to the project's innovation } \\
\text { The possibility of optimising the size, geometry and materials of the } \\
\text { designed construction } \\
\text { Enhancement of the functionality after allowing the possibility of electric } \\
\text { supply. }\end{array}$ & $\begin{array}{l}\text { - The possibility of the lack of interest on the part of } \\
\text { companies due to a health risk for the user. }\end{array}$ \\
\hline
\end{tabular}

\section{References}

[1] PROCHOWSKI, L., ZUCHOWSKI, A.: Automotive Vehicles (in Polish), Technika transportu ladunkow : Wydawnictwa Komunikacji i Lacznosci, Warszawa 2009

[2] VACULIK, J., KOLAROVSZKI, P., TENGLER, J.: Results of Automatic Identification of Transport Units in Postal Environment, Transport and Telecommunication, vol. 13, No. 1, 75-87. 
[3] COREJOVA, T., IMRISKOVA, E.: Convergence at the Postal Market, Eksploatacja $i$ niezawodnosc-Maintenance and Reliability, vol. 1, No. 3, 2008, 74-76,

[4] COREJOVA, T., ROSTASOVA, M., CHRENKOVA, A., MADUDOVA, E.: Regional Dimensions of Knowledge Processes in the Sectors of Transport and Logistics and ICT in the Zilina Region, Communications - Scientific Letters of the University of Zilina, vol. 15, No. 2, 2013, 25-33.

[5] Norma PN-EN 1756-1:2008 - Tail Lifts. Platform Lifts for Mounting on Wheeled Vehicles. Safety Requirements. Part 1: Tail Lifts for Goods (in Polish).

[6] LUBCZYNSKI, M., MAZUREK, S.: Self-unloading Car (in Polish), Wydawnictwa Komunikacji i Lacznosci : Warszawa 1978.

[7] MAdLenaKovA, L., MATUSKOVA, M., HRUDKAY, K.: Intermodal Transport Terminals as Part of the Postal Transportation Network. Transport Means 2016: $20^{\text {th }}$ intern. Scientific Conference, Kaunas University of Technology, ISSN 1822-296 X, 565-561.

[8] MADEJ, B., MICHNIK, J., MADEJ, R., KURCZ, J.: Road Transport of Passengers and Goods (in Polish), Podracznik kierowcy zawodowego. Akademia Transportu i Przedsiabiorczosci Sp. z o.o. : Warszawa 2014.

[9] ELLISON R., TEYE C., HENSHER, D.: Modelling Sydney's Light Commercial Service Vehicles. Transportation Research Part A: Policy and Practice, vol. 96, 2017, 79-89.

[10] DIETRICH, M. (red.): Fundamentals of Machine Design (in Poland), Tom 1.WNT, Warszawa, 1999.

[11] KOZMINSKI, A., PIOTROWSKI, W. (red.): Management. Theory and Practice (in Polish), Wydawnictwo Naukowe PWN : Warszawa 2013.

[12] SUDABE S., REZA A., MASAUD M., JAMAL G.: Application of Multi-Attribute Decision-Making Methods in SWOT Analysis of Mine Waste Management. Resources Policy, vol. 51, 2017, 67-76. 